\title{
Superhydrophobic Films from Raspberry-like Particles
}

\author{
W. Ming*, D. Wu, R. van Benthem, G. de With
}

\section{Supporting Information}

\section{Experimental}

\section{Materials}

Tetraethoxysilane (TEOS) and (bis)aminopropyl terminated polydimethylsiloxane (DMSA15) were obtained from ABCR; trimethylolpropane triglycidyl ether (TPTGE), 3glycidoxypropyl trimethoxysilane (GPS, 98\%), 3-aminopropyltriethoxysilane (APS, 98\%), and monoglycidyl ether terminated PDMS (MGE-PDMS, average MW = 5000) were obtained from Aldrich; Jeffamine D-230 (a polyoxypropylene diamine, amine-hydrogen equivalent weight $=60$ ) was obtained from Huntsman. Ammonia solution (25\%) was purchase from Merck. All chemicals were used without further purification.

\section{Preparation of amino-functionalized silica nanoparticles}

First, monodispersed silica particles of about $70 \mathrm{~nm}$ in diameter were prepared by polymerization of TEOS, according to the Stöber method. ${ }^{21}$ Briefly, $6 \mathrm{~mL}$ of TEOS was added dropwise, under magnetic stirring, to a flask containing $15 \mathrm{~mL}$ of ammonia solution (25\%, catalyst) and $200 \mathrm{~mL}$ of ethanol. The reaction was carried out at $60{ }^{\circ} \mathrm{C}$ for $5 \mathrm{~h}$, followed by the addition of $0.3 \mathrm{~mL}$ of APS in $5 \mathrm{~mL}$ of ethanol. The stirring was continued for $12 \mathrm{~h}$ under $\mathrm{N}_{2}$ atmosphere at $60^{\circ} \mathrm{C}$. The nanoparticles were separated by centrifugation and the supernatant was discarded. The particles were then washed by ethanol three times. The white powder was vacuum-dried at $50{ }^{\circ} \mathrm{C}$ for $16 \mathrm{~h}$. The existence of amine groups at the surface of silica nanoparticles was examined by the ninhydrin test (for instance, (a) Moore, S.; Stein, W. H. J. 
Biol. Chem. 1954, 211, 907; (b) Eiselt, P.; Lee, K. Y.; Mooney, D. J. Macromolecules

1999, 32, 5561). The amino-functionalized silica particles were added into 5\% ninhydrin aqueous solution at room temperature. The color of the particles turned blue within a few min, indicating the successful grafting of amine moieties on the silica particle surface.

\section{Preparation of epoxy-functionalized silica microparticles}

Bare silica particles of $700 \mathrm{~nm}$ in diameter were synthesized first. At room temperature, 10 $\mathrm{mL}$ of TEOS was added dropwise, under magnetic stirring, to a flask containing $21 \mathrm{~mL}$ of ammonia solution, $75 \mathrm{~mL}$ of isopropanol, and $25 \mathrm{~mL}$ of methanol. After $5 \mathrm{~h}$, the particles were separated by centrifugation, washed with distilled water/ethanol, and vacuum-dried at $50{ }^{\circ} \mathrm{C}$ for $16 \mathrm{~h}$. Then $1.5 \mathrm{~g}$ of silica microparticles were redispersed into $40 \mathrm{~mL}$ of dry toluene, and $0.2 \mathrm{~g}$ of GPS in $5 \mathrm{~mL}$ dry toluene was added dropwise to the silica suspension with vigorous stirring. The suspension was stirred at $50{ }^{\circ} \mathrm{C}$ under $\mathrm{N}_{2}$ atmosphere for $24 \mathrm{~h}$. The particles were then separated by centrifugation and washed with toluene three times. The white powder was vacuum-dried at $50{ }^{\circ} \mathrm{C}$ for $16 \mathrm{~h}$.

Preparation of amino-functionalized raspberry-like silica particles

Amino-functionalized silica nanoparticles $(0.4 \mathrm{~g})$ of were suspended in $20 \mathrm{~mL}$ of ethanol, and $0.6 \mathrm{~g}$ of epoxy-functionalized silica microparticles were suspended in $15 \mathrm{~mL}$ of ethanol, respectively. Afterwards, the silica microparticle suspension was added dropwise, under vigorous stirring, into the silica nanoparticle suspension. The suspension was refluxed for 24 h under $\mathrm{N}_{2}$ atmosphere. The particles were then separated by centrifugation and washed with ethanol three times. The white powder was vacuum-dried at $50{ }^{\circ} \mathrm{C}$ for $16 \mathrm{~h}$.

Creation of epoxy-amine films with dual-size surface roughness

First, an epoxy-amine film with the epoxy in $10 \%$ excess was prepared on aluminum substrates by the following procedure. $0.44 \mathrm{~g}$ of TPTGE and $0.24 \mathrm{~g}$ of Jeffamine D-230 were dissolved in $1 \mathrm{~mL}$ of toluene, with an epoxy/amino molar ratio of about 2.2:1. Afterwards, a film 
of about $30 \mu \mathrm{m}$ (wet film thickness) was drawn down on an aluminum panel with an Erichsen automatic film applicator and then cured at $75^{\circ} \mathrm{C}$ for $2 \mathrm{~h}$. Next, a suspension of raspberry-like amino-functionalized silica particles in $1 \mathrm{~mL}$ ethanol was deposited on the epoxy layer by an automatic film applicator and then kept at $75{ }^{\circ} \mathrm{C}$ for $18 \mathrm{~h}$. After cooling down, the film was flushed with ethanol in a sonicator to remove loose particles, and dried at room temperature. Preparation of superhydrophobic films

The superhydrobhobic film was obtained by grafting PDMS onto the double-structured film containing raspberry-like particles. The surface-roughened film was first reacted with (bis)aminoend-capped PDMS (DMS-A15) at $80{ }^{\circ} \mathrm{C}$ for $4 \mathrm{~h}$ to ensure that any remaining epoxy groups from either epoxy-based film or large silica particles were converted into terminal amine groups; after the reaction the film was thoroughly washed by toluene to remove unreacted DMS-15. In the end, the film was reacted with mono-epoxy-end-capped PDMS (MGE-PDMS) at $80{ }^{\circ} \mathrm{C}$ for $4 \mathrm{~h}$ and followed by washing with toluene, resulting in a layer of PDMS covering the roughened surface.

For comparative purpose, a film containing only large silica particles was prepared as follows (reaction conditions are the same with above). An epoxy-based film was prepared with $10 \%$ epoxy in excess, followed by the surface grafting of large silica particles (containing amino groups at surface). Loose large particles were removed by flushing with ethanol in a sonicator. Finally MGE-PDMS was grafted to the film.

\section{Characterization}

Transmission electron microscopy (TEM) experiments were performed with a JEOL JEM2000FX TEM at $80 \mathrm{KV}$. Traditional negative plates were used for the data recording. The negatives were digitized using a scanner (Agfa DUO Scanner) working in grade mode with 8bits/channel of grayscale. The samples were prepared by dispersing silica particles in ethanol and depositing one drop of the dilute suspension on a copper grid coated with a carbon membrane.

AFM measurements were preformed on a Solver P47H instrument (NT-MDT) in no-contact 
mode. The cantilever of choice was no-contact gold-coated NSG 11S, and a typical resonance frequency used was $140 \mathrm{KHz}$. Contact angles and roll-off angles were measured with deionized water on a Dataphysics OCA 30 instrument at room temperature $\left(\sim 21^{\circ} \mathrm{C}\right)$. All the contact angles and roll-off angles were determined by averaging values measured at three different points on each sample surface. Dynamic advancing and receding angles were recorded while the probe liquid was added to and withdrawn from the drop, respectively. 